\title{
Plantar Pressure Evaluation during the Season in Five Basketball Movements
}

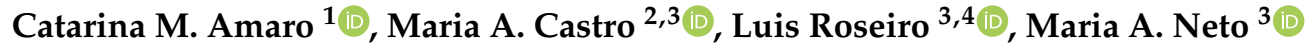 \\ and Ana M. Amaro ${ }^{3, *(\mathbb{D}}$ \\ 1 University of Coimbra, 3000 Coimbra, Portugal; catarinammamaro@gmail.com \\ 2 Polytechnic Institute of Coimbra, ESTeSC, 3046-854 Coimbra, Portugal; mac@estescoimbra.pt \\ 3 University of Coimbra, Center for Mechanical Engineering, Materials and Processes (CEMMPRE), \\ Department of Mechanical Engineering, 3030-788 Coimbra, Portugal; lroseiro@isec.pt (L.R.); \\ augusta.neto@dem.uc.pt (M.A.N.) \\ 4 Polytechnic Institute of Coimbra, ISEC, 3030-199 Coimbra, Portugal \\ * Correspondence: ana.amaro@dem.uc.pt; Tel.: +35-12-397-907-00
}

Received: 14 October 2020; Accepted: 2 December 2020; Published: 4 December 2020

\begin{abstract}
Sports activity is extremely important in the health context, with a clear motivation for its practice. One of the sports that involve more athletes is basketball, where the human body undergoes rapid reactions, emphasizing the contact of the foot with the ground. The main goal of the present study is to evaluate the distribution of plantar pressure in five different basketball movements. Supported by a group of nine volunteer female athletes from a senior basketball team, a data acquisition protocol was defined to identify the changes that occur throughout the sports season. In this study, the maximum values of plantar pressure were evaluated for both feet. The five movements that were defined and studied are all movements that might be performed during the basketball practice period. To guarantee the necessary conditions of data reliability and repeatability, at least seven repetitions were performed for each movement, which occurred at two different moments of the sports season: at the beginning of the competition in November, and at season peak, four months later, in March. Overall, the results obtained did not present statistically significant changes between the two seasons in this study. However, a slight decrease was observed throughout the sporting season for all movements, except for the rebound, where there was a contrary evaluation. Additionally, athletes with a higher level of experience show higher values of plantar pressure than less experienced athletes.
\end{abstract}

Keywords: basketball; plantar pressure; sports season; sports biomechanics

\section{Introduction}

In recent years, sports have become important in society, and basketball is no exception. Taking into consideration both the professional players and those who play for leisure, the number of basketball players in recent years has increased significantly. With this rise in popularity, competitiveness and intensity during training and games have also increased, and this can mean a higher possibility of getting injured. In basketball, the body parts with a greater risk of getting injured are the lower limbs, especially in female athletes [1]. According to Baker et al. [2], ankle injuries were one of the most frequent injuries in basketball players, and McCarthy et al. [3] concluded that female athletes suffer greater rates of injury compared with male athletes. As basketball is an intermittent sport, with long periods of moderate and recovery activity, there is a great propensity for injuries [4]. Hence, to avoid serious injuries in women's basketball, the intensity and frequency of training need to follow the chronological and biological age of each player [5]. Razak et al. [6] concluded that plantar pressure 
measurements are important for diagnosing lower limb problems, sports biomechanics, and injury prevention. Plantar pressure is not only used in sports but is also used to follow pathological conditions, for instance, in diabetes, to evaluate plantar ulcer prediction [7-9]. Plantar pressure assessment may also be useful to optimize basketball footwear designs, orthosis use, or training strategies to reduce injuries during a basketball game [10]. According to Serrano et al. [11], the human body comes into contact with the floor via the landing surface, and that means the lower limbs have a further likelihood of getting injured in high-contact sports, like basketball. Basketball is considered a sport of quick changes in velocity and intensity, and, for females, the rate of injuries per 1000 athlete exposures in the game is 4.2 and in practice is 2.24 , with an overall rate of injury of 2.86 per 1000 athlete exposures [12]. The list of technical and tactical arguments that can be used by a basketball player is extensive [13]. Using the plantar pressure measurement to relate foot pressure and the biomechanics function of the lower limbs to the increased training sessions along the season [14], it can be seen that the athletes' shoes begin to deteriorate, which can influence the athletes' performance [15]. This evaluation helps us to understand foot injuries, especially in people with pathological problems like Parkinson's, diabetes, and rheumatic arthritis, and we can also identify the areas of the foot that are most susceptible to skin injuries [16-21]. Plantar pressure may be evaluated by several methods; one of them is shoe systems, which are more flexible than other methods like pressure distribution platforms and are positioned inside the shoes, allowing for a better adjustment to the athlete [22,23]. Usually, the parameters of interest when evaluating plantar pressure are peak pressure (PP; considered the maximum plantar pressure), pressure time integral (PTI; commonly defined as the area under the peak pressure-time curve), and mean peak pressure (mPP) [15,24-27]. Nevertheless, Waaijman and Bus [27] and Melai et al. [28] have concluded that MPP and PTI values are highly interdependent, and it is not necessary to evaluate both.

This study aims to evaluate plantar pressure in five different basketball movements-four with running and only one without running - and compare them at two different moments of the sports season: at the beginning and at the peak of the competition season. It also aims to verify if the athletes' level of experience could influence the mean peak plantar pressure. To assess the effect of the athletes' experience level, they were divided into two groups: one included the least experienced players and the other the most experienced, according to the number of games played. In this group division, it was also considered whether or not the athlete belonged to the elite regional basketball team. Additionally, a comparison between plantar pressure for the left foot and the right foot was made. The presence of asymmetry between the feet can be an indication that there has been a negative impact on normal foot function and unequal loading of the two feet during the movements. Hence, the symmetry index of all five basketball movements was analyzed.

\section{Materials and Methods}

\subsection{Participants}

Before participation in this study, all the athletes were fully informed of the nature of the investigation and gave written informed consent. The study was approved by the ethical committee of the Polytechnic of Coimbra (CEPC 26/2018) and performed according to the Declaration of Helsinki; all the participants' data have been registered and stored anonymously.

The group was initially formed by eleven female basketball athletes, with ages between 18 and 23 years and at least six years of experience in this sport. During the season, one of the athletes was injured, and another, for family reasons, gave up the sport. Therefore, the final group constituted of nine athletes. Table 1 shows the age, height, body mass index, favorite hand, and years of practice of each athlete. The mean age was 19.9 years, and the years of practice were around 11. 
Table 1. Volunteers' relevant characteristics.

\begin{tabular}{|c|c|c|c|c|}
\hline Athlete ID & Age (Years) & Height (m) & Body Mass Index $\left(\mathrm{kg} \cdot \mathrm{m}^{-2}\right)$ & Years of Practice \\
\hline 1 & 19 & 1.79 & 22.8 & 7 \\
\hline 2 & 19 & 1.66 & 24.3 & 12 \\
\hline 3 & 19 & 1.71 & 18.8 & 11 \\
\hline 4 & 22 & 1.64 & 26.2 & 17 \\
\hline 5 & 23 & 1.69 & 25.3 & 17 \\
\hline 6 & 21 & 1.58 & 28.0 & 7 \\
\hline 7 & 18 & 1.62 & 19.8 & 11 \\
\hline 8 & 19 & 1.60 & 24.0 & 6 \\
\hline 9 & 19 & 1.66 & 19.2 & 11 \\
\hline 10 & 21 & 1.63 & 20.7 & 15 \\
\hline 11 & 21 & 1.61 & 23.1 & 8 \\
\hline Mean \pm SD (initial sample) & $20.1 \pm 1.6$ & $1.65 \pm 0.06$ & $23.0 \pm 3.1$ & $11 \pm 4$ \\
\hline Mean \pm SD (final sample) & $19.9 \pm 1.7$ & $1.66 \pm 0.06$ & $23.2 \pm 3.3$ & $11 \pm 4$ \\
\hline
\end{tabular}

\subsection{Setup}

To evaluate the differences during the season, acquisitions were made at two different moments of the sports season: November (at the beginning of the competitive season; T1) and March (corresponding to the peak of the competition; T2), usually when 20 to 25 games have been played. Before the first acquisition, a ten-meter walk test (10 MWT) was performed to provide a walking characterization of each volunteer athlete. In the first session they attended, athletes were familiarized with all the study procedures and completed one exercise under each test condition. Later, following the test familiarization, all athletes performed at least seven quality acquisitions under each movement at both season moments, a total of 630 valid data points. The sequence of the movements was randomized (Table 2) for the players in order to minimize external factors like fatigue and routines and to avoid a learning bias. Between movements, the volunteers had one minute to rest, while between repetitions of the same movement, they had $30 \mathrm{~s}$ of rest.

Table 2. Movement randomization.

\begin{tabular}{cccccc}
\hline Athlete ID & 1st mov. & 2nd mov. & 3rd mov. & 4th mov. & 5th mov. \\
\hline 1 & RNB & LR & R & RB & LL \\
2 & LL & RNB & LR & R & RB \\
3 & LR & R & RB & LL & RNB \\
4 & RNB & LR & R & RB & LL \\
5 & LL & RNB & LR & R & RB \\
6 & RB & LL & RNB & LR & R \\
7 & R & RB & LL & RNB & LR \\
8 & LR & R & RB & LL & RNB \\
9 & RNB & LR & R & RB & LL
\end{tabular}

RB—running with the ball; RNB—running without the ball; LR—lay-up on the right side; LL—lay-up on the left side; $\mathrm{R}$-rebound.

The five movements or test conditions considered can be described as follows: RB-running with the ball; RNB — running without the ball; LR-lay-up on the right side; LL-lay-up on the left side; $\mathrm{R}$-rebound. Each one of these five basketball maneuvers needs the activation of the lower limbs, and their efficiency depends on the leg's strength, mobility, and coordination. Hence, for basketball players, their legs are undeniably important.

Data were acquired during team training, always in the same basketball gym, using a game ball with the recommended pressure of 0.62 bar. All players used their normal basketball shoes, and no one changed their shoes between the two acquisitions. 


\subsection{Instruments}

In-shoe plantar pressure was measured using the Pedar-x system (Novel ${ }^{\circledR}$, Munich, Germany). Before and after data collection, the insoles were checked using the Trublu ${ }^{\circledR}$ calibrating system (novel gmbh, Munich, Germany) to verify that all sensors were functioning accurately. This system contains 99 piezoresistive sensors, with a thickness of $1.9 \mathrm{~mm}$ and a pressure range of $637.5 \mathrm{kPa}$, $7 \%$ hysteresis, and a resolution of $2.5 \mathrm{kPa}$. The system allows the performance of the acquisition with a frequency of 50 or $100 \mathrm{~Hz}$. The insoles have different sizes; dimensions of 8/9 were used according to the participants' foot size and were comfortably placed between the socks and the basketball shoes. The connection between the signal amplifier and the computer was made via Bluetooth. A belt was used to lock the data logger to the waist of each basketballer for data storage. Pedar ${ }^{\circledR}$ software (novel gmbh, Munich, Germany) was used to record and process the evolution of plantar pressure for each foot in real-time. Considering all the sensors, each foot was divided into three different zones (Figure 1), the forefoot, midfoot, and rearfoot, being analyzed separately. The result includes all parts of the foot.

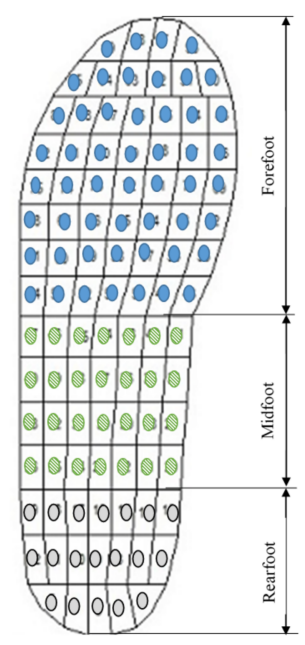

Figure 1. Plantar anatomic region divided into three zones.

\subsection{Data Processing}

The maximum value of mean peak pressure (mPP) was analyzed with the same method for all the acquisitions. First of all, we identified the feet zone with higher values; then, we measured the highest values for each acquisition; after this, the average value was calculated. The statistical package IBM SPSS Statistics 25.0 (IBM Corporation, New York, NY, USA) was used for statistical analyses [29]. The Wilcoxon test was considered to compare the two evaluated session moments (November and March), and the Friedman test was used for multiple nonparametric comparisons, like the comparison between experience level, foot, and movement. A significance level of 0.05 was defined to identify differences.

To evaluate the effect of plantar pressure on feet lateralization, the symmetry index (SI) [30-33] was considered, defined by

$$
S I[\%]=\frac{2 \times\left|\left(X_{1}-X_{2}\right)\right|}{\left(X_{1}+X_{2}\right)} \times 100
$$

where $X_{1}$ and $X_{2}$ are the values of plantar pressure for the right foot and the left foot, respectively.

According to Viteckova et al. [31] and Wu et al. [32], if SI is zero, the landing is symmetrical; when $S I$ is less than $10 \%$, the symmetry is considered to be acceptable; however, higher values of $S I$ can promote loss of bone mass density of one limb versus the other, as well as higher dynamic loads on the contralateral limb and joints. 


\section{Results and Discussion}

From the gait analysis performed during the $10 \mathrm{~m}$ walk test, it was possible to assess if athletes had similar plantar pressure distributions: seven athletes had a plantar pressure distribution with the pattern in Figure 2a, and only two athletes presented the pattern shown in Figure 2b. Comparing both distributions, it is possible to see that in Figure $2 b$, there was almost an absence of black color over the midfoot, while in Figure 2a, there is a large black-colored area. Hence, the pattern distribution of Figure $2 \mathrm{~b}$ makes the feet appear completely flat, with no space in the middle foot. However, after the first moment of acquisition, in November (T1), it was possible to conclude that the zones with higher pressures were practically the same for both types of feet, meaning that the nine athletes can be considered a group. In Figure 3, it is possible to qualitatively compare the zones with higher pressure for the two types of feet during the five movements evaluated.
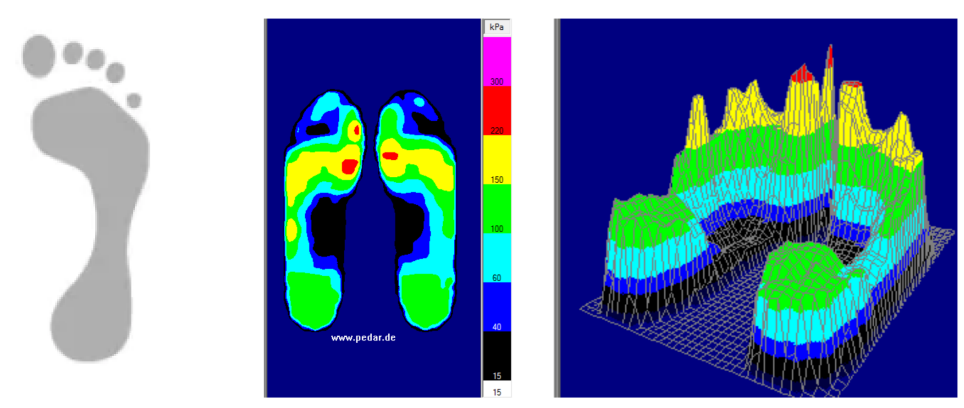

(a)
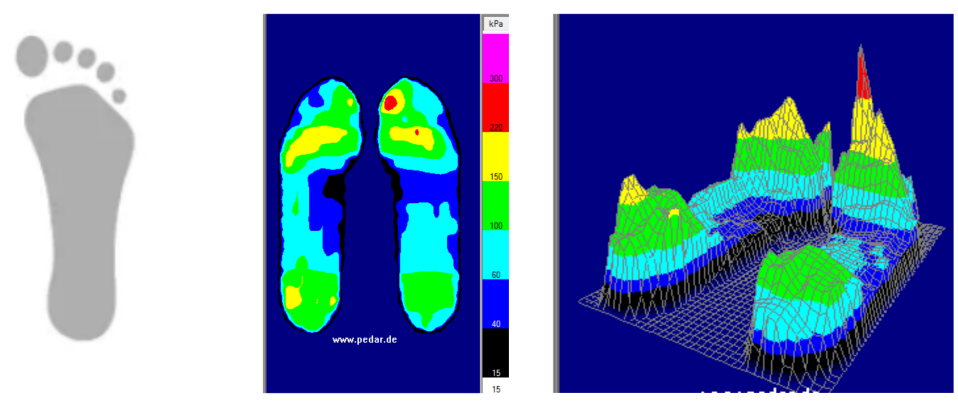

(b)

Figure 2. Plantar pressure distribution of athletes: (a) regular pattern; (b) flat pattern.

Table 3 shows the mPP for both feet at the two moments of the season, considering the five different movements. The higher standard deviation of these results could be the result of variability that is related to different physical and morphological characteristics. This table shows that there are no statistically significant differences in any of the comparisons. Despite that, minimum differences between both moments of acquisition can be observed, with higher values at the first moment of acquisition (T1). One of the factors that can influence this variation is the shoe insole, which could be damaged by use (getting stiffer); the saturation of the airbox that most shoes have can also influence the athlete's performance [15,34]. Harder shoes/insoles tend to increase plantar pressure values; however, in this study, the athletes always wore their normal shoes/insoles and, therefore, the actualized perceptual comfort of the shoes/insoles allowed, to some extent, the self-adjustment of movement intensity. Moreover, the variation in athletic performance indexes (APIs) between the two seasons may also be another factor that may well have contributed to these differences. 

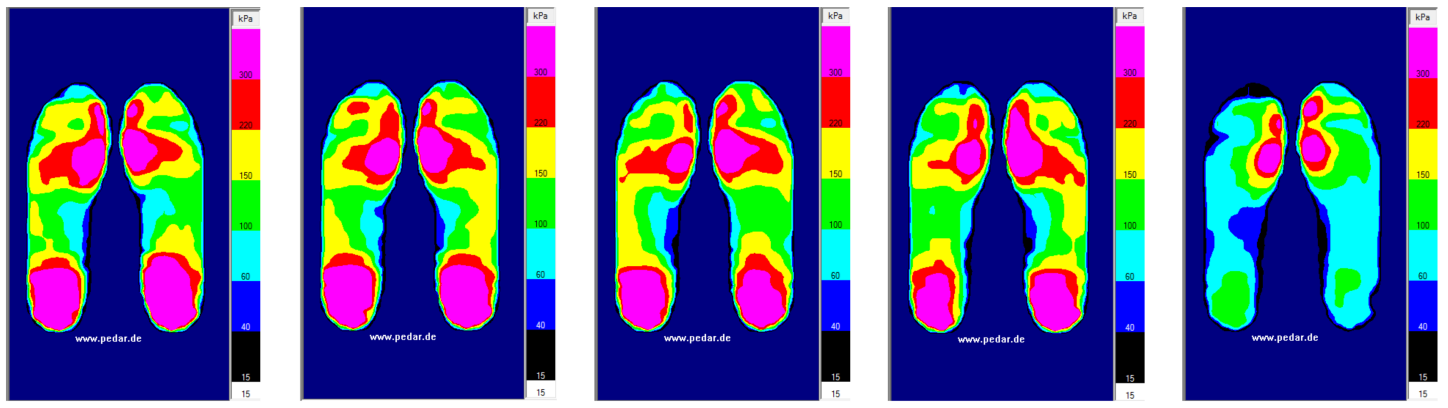

(A)

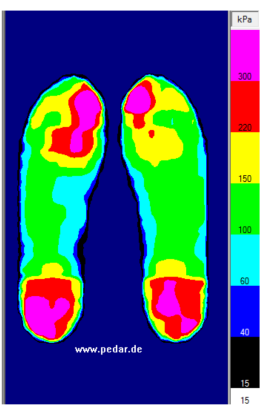

RB

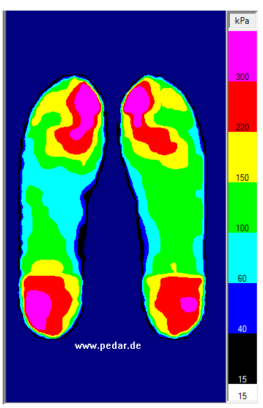

RNB

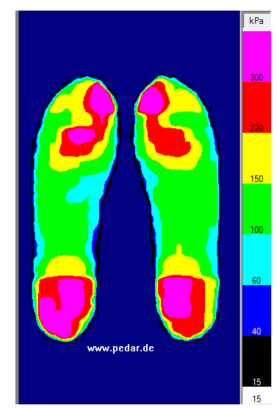

LR

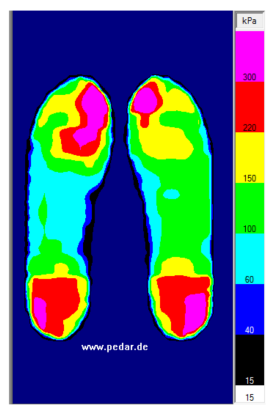

LL

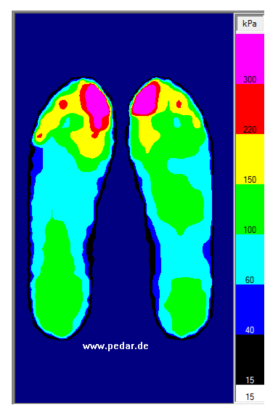

$\mathrm{R}$

(B)

Figure 3. (A) Athlete with regular pattern; (B) athlete with flat pattern.

Table 3. $\mathrm{mPP}-(\overline{\mathrm{X}})$ and standard deviation (SD). Comparison between the two season moments (T1, T2) and, in each season, between feet.

\begin{tabular}{ccccc}
\hline & & T1 $\bar{X} \pm \mathbf{S D}(\mathbf{k P a})$ & $\mathbf{T} 2 \overline{\boldsymbol{X}} \pm \mathbf{S D}(\mathbf{k P a})$ & $p$ \\
\hline \multirow{2}{*}{ RB } & Right Foot & $401.6 \pm 71.66$ & $393.0 \pm 103.5$ & 0.314 \\
& Left Foot & $419.7 \pm 61.2$ & $396.6 \pm 88.3$ & 0.173 \\
\hline \multirow{2}{*}{ RNB } & $p$ & 0.374 & 0.953 & \\
& Right Foot & $426.2 \pm 74.6$ & $381.1 \pm 105.2$ & 0.066 \\
& Left Foot & $416.9 \pm 50.5$ & $397.2 \pm 85.7$ & 0.374 \\
\hline \multirow{2}{*}{ LR } & $p$ & 0.859 & 0.515 & \\
& Right Foot & $383.6 \pm 46.4$ & $375.4 \pm 70.6$ & 0.484 \\
& Left Foot & $357.1 \pm 59.6$ & $360.5 \pm 85.2$ & 0.263 \\
\hline \multirow{2}{*}{ LL } & $p$ & 0.314 & 0.484 & \\
& Right Foot & $383.9 \pm 71.5$ & $351.0 \pm 77.7$ & 0.139 \\
& Left Foot & $372.3 \pm 37.3$ & $348.0 \pm 77.6$ & 0.086 \\
\hline \multirow{2}{*}{ R } & $p$ & 0.678 & 0.859 & \\
\hline \multirow{4}{*}{} & Right Foot & $295.0 \pm 52.7$ & $297.7 \pm 102.4$ & 0.575 \\
& Left Foot & $300.6 \pm 61.1$ & $350.7 \pm 87.6$ & 0.069 \\
\hline
\end{tabular}

RB — running with the ball; RNB—running without the ball; LR—lay-up on the right side; LL-lay-up on the left side; $\mathrm{R}$-rebound.

The basketball movement with the lowest plantar pressure values is related to the rebound (R) movement, i.e., the only movement that is not related to running in the majority of scenarios, except, for example, after a missed free throw, where $\mathrm{R}$ can be associated with a short run to the jump movement. On the other hand, the highest plantar pressures appear in the movements that include 
running tasks and especially in those at the beginning of the movement, RB and RNB, which present a race over a greater distance. This behavior can be one of the reasons why the distribution of plantar pressures related to sports studies is mostly related to dynamic movements rather than static ones [35].

Moreover, comparisons between right and left feet for the five basketball movements also did not present statistically significant differences. Small differences between right and left feet T1 and T2 were observed, and mPP at T2 was lower than at T1. Although the technique is improved and the movements performed more correctly with the increase in the number of training sessions, wear on the shoe begins to be observed, which can influence the athlete's performance [15]. Hence, sports shoe conditions, with the increasing number of training sessions, can be softer and allow a reduction in plantar pressure value induced during sports practice. According to Ke et al. [34], the type of sole and its condition is very important, not only for the comfort of the athlete but also to relieve the induced pressure and, thus, decrease the probability of the athlete suffering injuries.

Figure 4 illustrates the distribution of plantar pressure represented by zones and with 3D responses, which allows the assessment of the magnitude of the observed plantar pressure value. This figure shows the results for an athlete performing the five movements at $\mathrm{T} 1$ and $\mathrm{T} 2$ and is representative of the results obtained for all athletes with the flat foot type.

(T1)
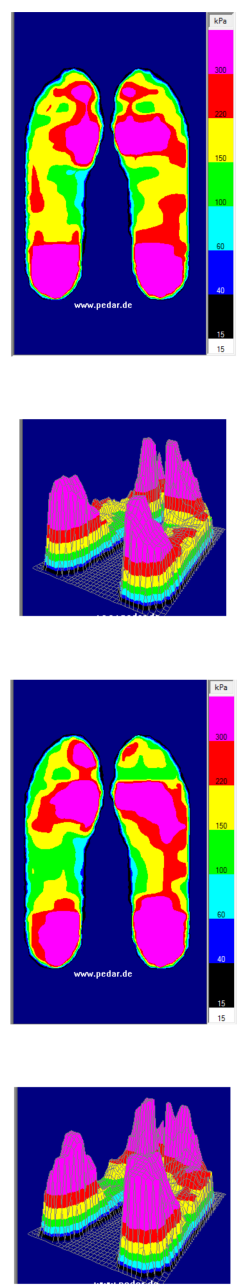

$\mathrm{RB}$
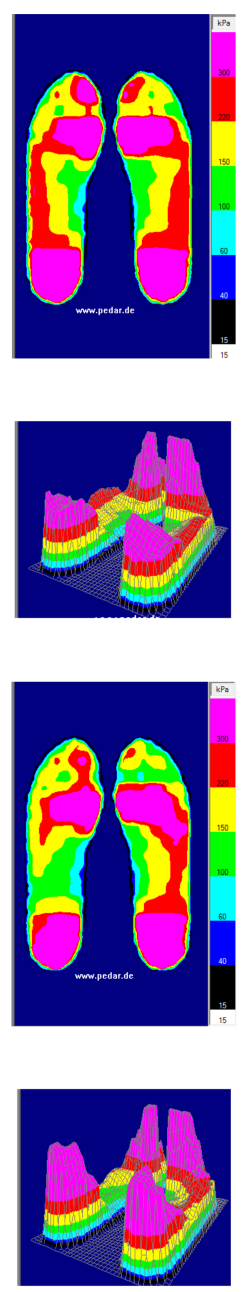

RNB
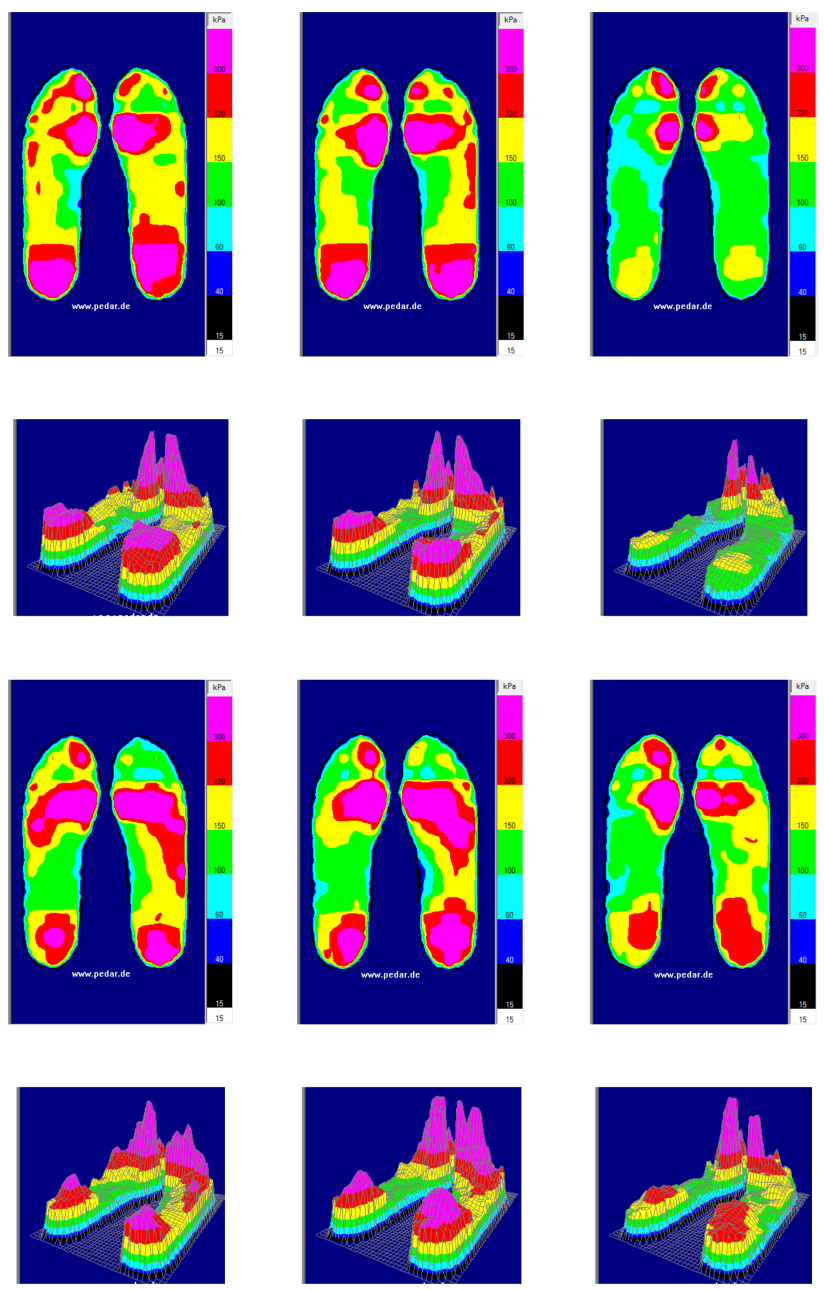

LR

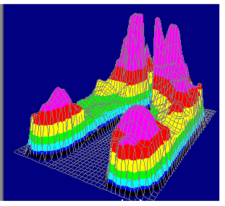

LL

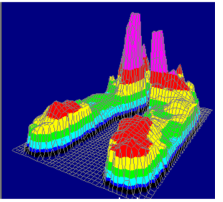

$\mathrm{R}$

Figure 4. Examples of plantar pressure distributions: comparison between the two assessment times, T1 (November) and T2 (March). 
Figure 4 shows that there is a similarity between the acquisitions concerning the most solicited zones of the foot, with the hallux and rearfoot having higher values. These results follow those obtained by Sterzing et al. [36], who reported that the most requested areas of the foot during running are identified in the rearfoot. After the distribution of plantar pressure is known, it is possible to identify the plantar areas where the highest pressure is exerted in order to help coaches to apply corrective training measures, if necessary. High values of plantar pressure can originate injuries, and athletes are advised to wear appropriate insoles and/or to adapt their work plan during practice [36,37]. However, in this investigation, the highest values observed for all the athletes were lower than those identified by Elis et al. [37], who noted that the foot values that can cause injuries are around $600 \mathrm{kPA}$ for the hindfoot (rearfoot) and forefoot and $500 \mathrm{kPa}$ for the hallux. In Figure 4, it is possible to see that basketball movements that include running (LPD, LPE, ACB, and ASB) are the movements that show higher values of plantar pressure, mainly in the forefoot; these results agree with those reported by Kong et al. [10].

Table 4 illustrates the results of Friedman's test for the comparison of all the movements performed by the athletes. The test was separately performed for both feet using the data from all movements at the two assessment times (T1 and T2). Regarding the results of Table 4, it is possible to conclude that there are statistically significant differences between the movements at both times.

Table 4. Friedman test results for individual comparison of each foot and time in all movements.

\begin{tabular}{ccc}
\hline & T1 & T2 \\
\cline { 2 - 3 } & $\mathbf{m P P}$ & $\mathbf{m P P}$ \\
\hline Right foot & $<0.05$ & 0.014 \\
Left foot & $<0.05$ & 0.013 \\
\hline
\end{tabular}

To correctly identify the movements where more significant differences occur, a statistical analysis comparing the five movements was performed for each evaluation moment (T1 and T2; see Table 5).

Table 5. Friedman test results comparing the five movements at $\mathrm{T} 1$ and $\mathrm{T} 2$, individually.

\begin{tabular}{ccccccc}
\hline & Movement & Foot & RNB & LR & LL & R \\
\hline \multirow{4}{*}{ RB } & Right & $>0.05$ & $>0.05$ & $>0.05$ & 0.046 \\
& Left & $>0.05$ & 0.113 & 0.736 & 0.001 \\
\hline \multirow{3}{*}{ T1 } & RNB & Right & & $>0.05$ & 0.526 & $<0.05$ \\
& Left & & 0.113 & 0.736 & 0.001 \\
\cline { 2 - 6 } & \multirow{2}{*}{ LR } & Right & & & $>0.05$ & 0.006 \\
& Left & & & $>0.05$ & $>0.05$ \\
\hline \multirow{2}{*}{ LL } & Right & & & & 0.253 \\
& Left & & & & 0.369 \\
\hline \multirow{2}{*}{ RB } & Right & $>0.05$ & 0.820 & 0.398 & 0.005 \\
& Left & $>0.05$ & 0.177 & 0.177 & 0.820 \\
\hline \multirow{2}{*}{ RNB } & Right & & $>0.05$ & $>0.05$ & 0.398 \\
& Left & & 0.114 & 0.114 & 0.578 \\
\hline \multirow{2}{*}{ LR } & Right & & & $>0.05$ & 0.820 \\
& Left & & & $>0.05$ & $>0.05$ \\
\hline \multirow{2}{*}{ LL } & Right & & & $>0.05$ \\
& Left & & & $>0.05$ \\
\hline
\end{tabular}

RB—running with the ball; RNB—running without the ball; LR—lay-up on the right side; LL-lay-up on the left side; R-rebound. 
The results from Table 5 show that the R movement has the greatest discrepancy to the others. It is also verified that from $\mathrm{T} 1$ to $\mathrm{T} 2$, the values become more uniform with each other, and the only basketball movements that revealed statistically significant differences are RB and R. This information could be important for medical diagnostics, rehabilitation, coaches, and athletes to improve sports performance and reduce injury occurrence. If coaches knew which movements induced higher plantar pressure values at what stage of the season, they could develop training plans to prevent injuries. The coaches could promote specific training that is capable of responding to the effort required for certain movements, for example, through adequate muscle strengthening.

To verify if the level of experience could influence these results, the mPP values of the group with more experienced athletes (1) were compared with those of the less experienced (2) group (see Table 6 and Figure 5).

Table 6. Results considering the two experience levels for the five movements (Mov) at T1 and T2.

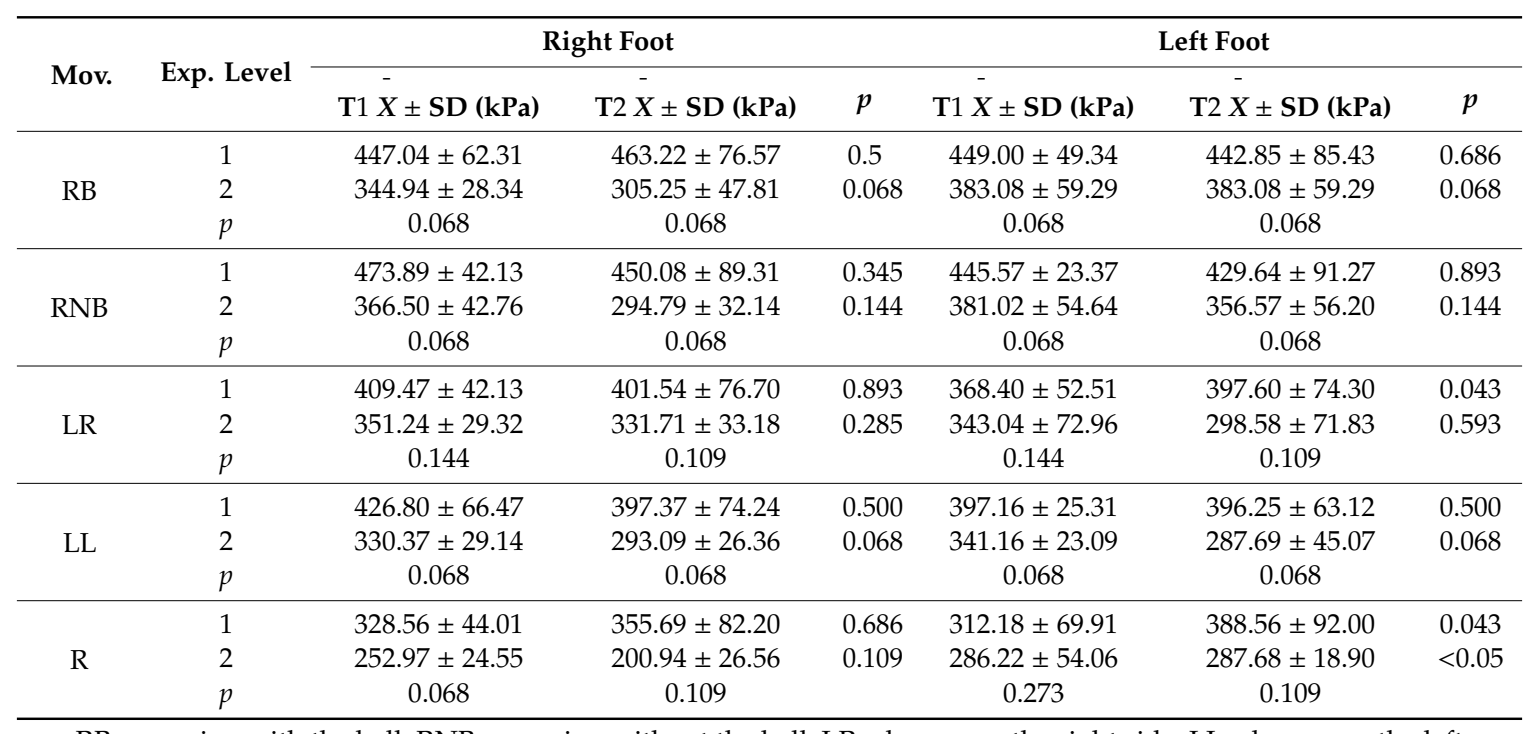

RB — running with the ball; RNB—running without the ball; LR—lay-up on the right side; LL-lay-up on the left side; $\mathrm{R}$-rebound.

No statistical differences were found between levels of experience (Table 6). Nevertheless, it appears that the more experienced players always have higher values of mPP than the less experienced ones but also less symmetry concerning the right and left feet, with the right foot showing higher values of mPP. In less experienced athletes, a greater discrepancy of values was identified, and it was not possible to recognize which foot is dominant. In terms of the type of movement, the lowest mPP corresponded to $\mathrm{R}$ but with no significant difference between the other movements. Once more, this behavior can be justified by the fact that $\mathrm{R}$ is the only movement that does not have associated running; according to Kong et al. [10], running induces higher plantar pressure values. Less experienced athletes can perform all movements more defensively, so such high plantar pressure values are not induced.

Table 7 shows the values obtained by Equation (1) concerning all the test conditions, movements, moments of the season, and athlete levels. From Table 7, it can be observed that the less experienced athletes showed higher SI values than the athletes with higher experience. Moreover, the highest value of SI at both times appears for the rebound movement. According to Wafai et al. [21], the presence of asymmetry between feet can be an indication that there has been a negative impact on normal foot function and unequal loading of the two feet during the movements because the run and jump are frequently assumed to be symmetrical. Athletes tend to obtain a more identical response between limbs with an increase in the number of years of experience [38]. 


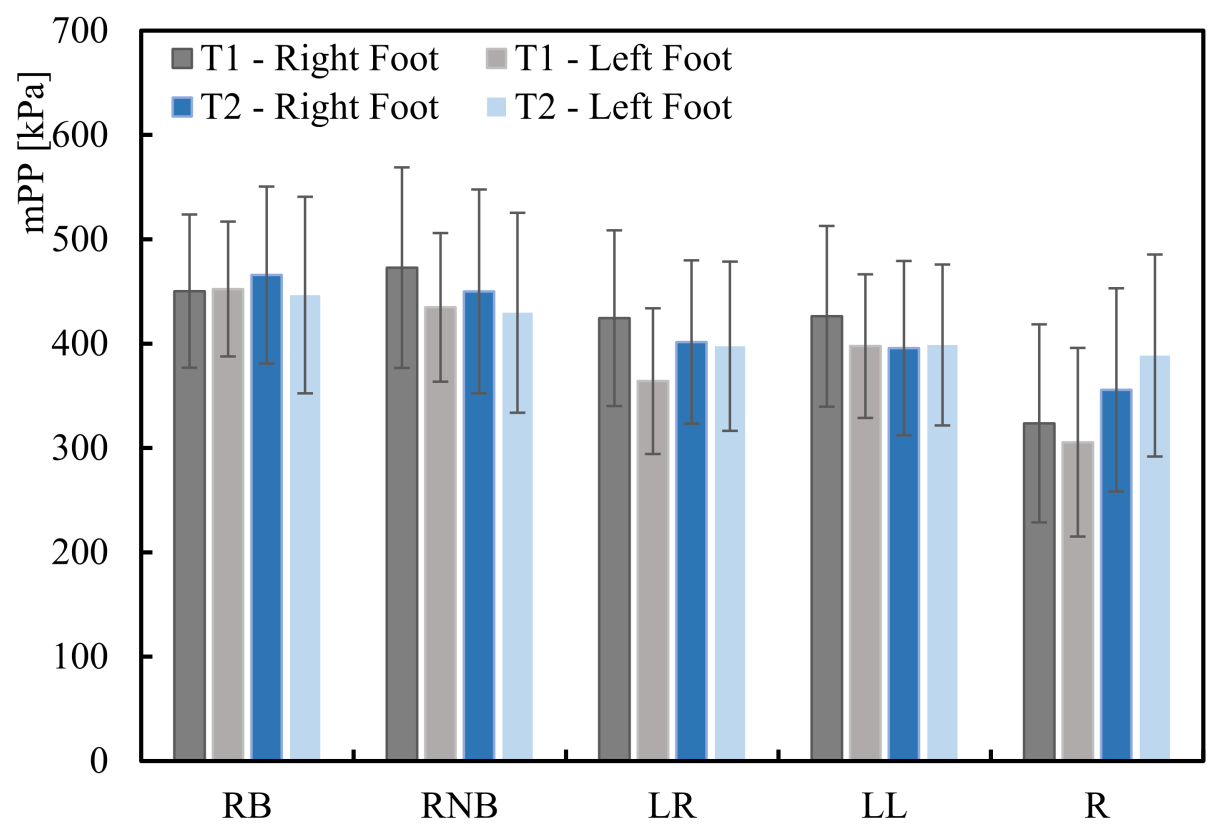

(a)

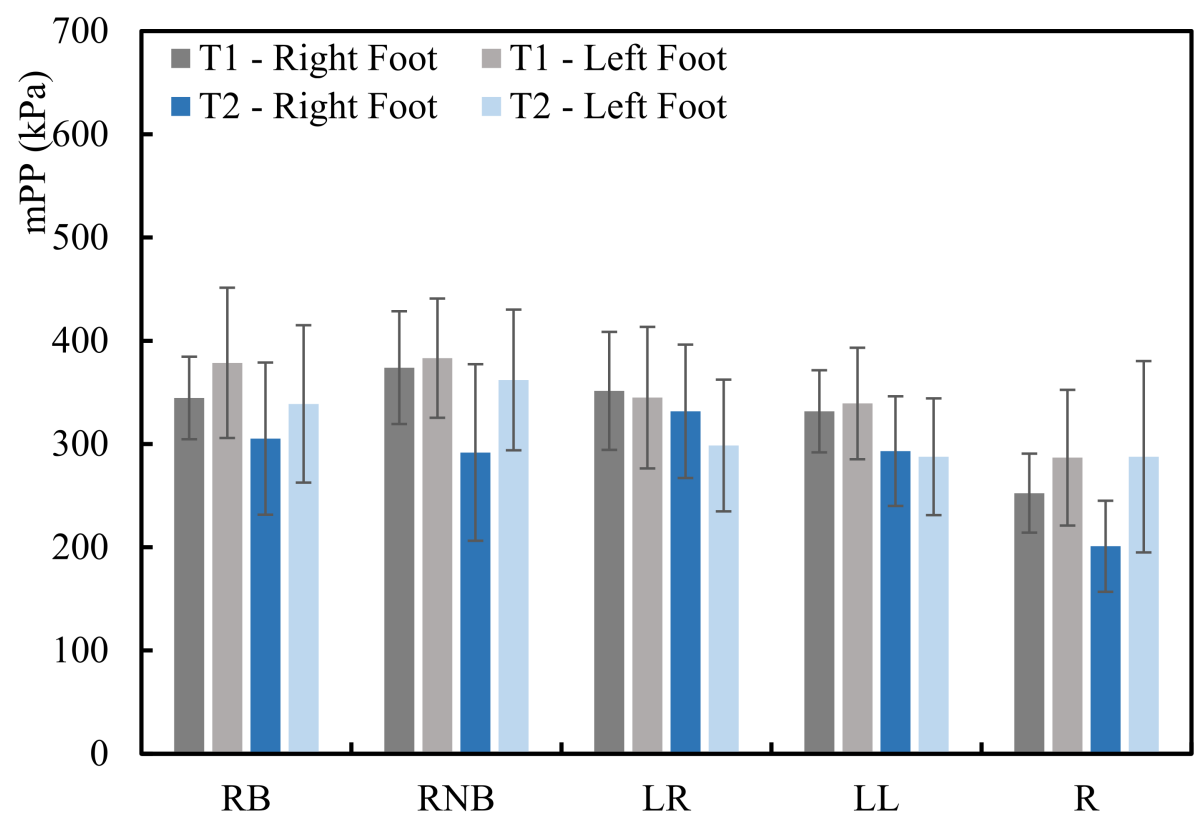

(b)

Figure 5. Mean peak pressure (mPP): (a) Level 1; (b) Level 2. RB-running with the ball; RNB — running without the ball; LR—lay-up on the right side; LL_lay-up on the left side; R—rebound.

According to Yu et al. [39], identifying the distribution of plantar pressure can help athletes and their coaches to prevent injuries. These injuries can be caused by the high number of repetitions of the exercises but can also be due to poorly performed exercises. Kong et al. [10] reported that normal running and sprinting are the most repeated movements in basketball, which can lead to pressures in the order of $360 \mathrm{kPa}$. Note that, today, there are several studies on the development of footwear for basketball players to create greater cushioning in the rearfoot, a highly requested area during basketball practice. The value of $360 \mathrm{kPa}$ is observed in almost all the movements with running, principally for the more experienced athletes. The intensity imposed during basketball training by 
the most experienced athletes could be greater than that imposed by the remaining athletes. On the other hand, less experienced athletes are more careful in performing the exercises, as they are not as confident in the way they perform them; hence, the plantar pressure could be lower.

Table 7. Symmetry index for the athletes under all test conditions.

\begin{tabular}{cccc}
\hline \multirow{2}{*}{ Mov } & \multirow{2}{*}{ Exp. Level } & SI (\%) & SI (\%) \\
\cline { 3 - 4 } & & T1 & T2 \\
\hline \multirow{2}{*}{ RB } & 1 & 0.4 & 4,5 \\
& 2 & 10.5 & 22.6 \\
\hline \multirow{2}{*}{ RNB } & 1 & 6.2 & 4.6 \\
& 2 & 3.9 & 18.9 \\
\hline \multirow{2}{*}{ LR } & 1 & 10.6 & 0.98 \\
& 2 & 2.4 & 10.5 \\
\hline \multirow{2}{*}{ LL } & 1 & 7.2 & 0.28 \\
& 2 & 3.2 & 1.9 \\
\hline \multirow{2}{*}{ R } & 1 & 5.1 & 8.8 \\
& 2 & 12.3 & 35.5
\end{tabular}

RB — running with the ball; RNB—running without the ball; LR—lay-up on the right side; LL-lay-up on the left side; $\mathrm{R}$-rebound.

This study was developed at the academy under normal training conditions and not highly controlled laboratory conditions. The experimental setup was carried out by considering the pressure sensitivity of the foot, the impacts of the external load, and the duration of the test. However, individual factors of the athletes, such as foot morphology and body mass, were not included as experimental parameters. Additionally, the number of athletes (nine at the end) may not have been enough to extrapolate the results. It is important to emphasize that the study protocol did not specify that the athletes needed to wearing shoes/insoles of the same brand and model, but nearly all shoes were of the same brand. As suggested by several studies [15], the pattern of plantar pressure distribution and their maximum values may be affected by the type of shoes. Nevertheless, the main goal of the present study was not to study the influence of the hardness effect of the shoes/insoles on plantar pressure but to evaluate the distribution of plantar pressure in five different basketball movements and if there were statistical differences among the maximum values of mean peak pressure of each movement. Notice that because each athlete was always wearing the same shoes, it is expected that the data effects of the shoes will be the same over all movements and over the two seasons. On a normal training day, the athletes do not change their preferred shoes/insoles and, therefore, to perform this study, it was not necessary to ensure similar shoes/insoles for each athlete. Moreover, in addition to meeting the functional requirements of specific sporting events and strengthening foot protection, the most important element in specialized sports shoes is comfort. Hence, if the normal shoes/insoles of each athlete were changed, we might also have changed the athlete's comfort perception and, therefore, changed their performance of the five basketball movements.

Despite these limitations, the results provided useful information that can help coaches and athletes develop training methodologies to avoid the occurrence of injuries.

\section{Conclusions}

In the present study, no significant statistical differences were found between the two moments of the season. At the beginning of the competitive season, plantar pressure values were higher for all the movements except the rebound movement, where the results are higher at the peak of competition. After the comparison between movements, there were only differences for RNB and LL with R at T1 and $\mathrm{RB}$ with $\mathrm{R}$ at $\mathrm{T} 1$ and $\mathrm{T} 2$, which confirm that the rebound (R) movement is the movement with different values, in this case, the lowest value. This movement is the only one of the five performed that does 
not have running associated with it, which may be a factor of differentiation. The comparison between the two groups, with different levels of experience, showed no statistical difference, but, generally, the group of the most experienced players performed at higher values. The more experienced athletes showed an acceptable degree of symmetry in MPP values, but the mean SI value of athletes had the tendency to grow for the less experienced players, especially for the second moment of the season. The results obtained can be a great help to coaches for developing training methodologies that can reduce the occurrence of injuries. With the knowledge of which movement is most conducive to injuries, coaches will reduce, if possible, the number of repetitions of that movement during training. Moreover, the athletes, having verified that the differences observed in the two phases of the season may be associated with the wear of the soles of their shoes, should try to evaluate the condition of their shoe soles more frequently and also choose a shoe adapted to basketball, with reinforcement in the rearfoot.

Author Contributions: M.A.C., L.R., and A.M.A. conceived and designed the study; C.M.A. performed the tests, analyzed the results, and helped to write the manuscript; M.A.C., L.R., and A.M.A. participated in the research work and helped to write the manuscript. C.M.A., M.A.C., L.R., M.A.N., and A.M.A. contributed to the acquisition, analysis, and interpretation of data, and helped to write the manuscript. All authors have read and agreed to the published version of the manuscript.

Funding: This research was sponsored by FEDER funds through the program COMPETE-Programa Operacional Factores de Competitividade and by national funds through FCT-Fundação para a Ciência e a Tecnologia, under the project UIDB/00285/2020. and the Mais Centro Program, Center Region Coordination Committee of EU through European Regional Development Fund.

Conflicts of Interest: Authors declare no conflict of interest.

\section{References}

1. Deitch, J.R.; Starkey, C.; Walters, S.L.; Moseley, J.B. Injury Risk in Professional Basketball Players: A comparison of Women's National Basketball Association and National Basketball Association athletes. Am. J. Sports Med. 2006, 34, 1077-1083. [CrossRef]

2. Baker, H.; Rizzi, A.; Athiviraham, A. Injury in the Women's National Basketball Association (WNBA) From 2015 to 2019 Arthroscopy, Sports Medicine, and Rehabilitation. Arthrosc. Sports Med. Rehabil. 2020, 2, e213-e217. [CrossRef] [PubMed]

3. McCarthy, M.M.; Voos, J.E.; Nguyen, J.T.; Callahan, L.R.; Hannafin, J.A. Injury Profile in Elite Female Basketball Athletes at the Women's National Basketball Association Combine. Am. J. Sports Med. 2013, 41, 645-651. [CrossRef] [PubMed]

4. Ben Abdelkrim, N.; El Fazaa, S.; El Ati, J. Time-motion analysis and physiological data of elite under-19-year-old basketball players during competition. Br. J. Sports Med. 2007, 41, 69-75. [CrossRef] [PubMed]

5. Stojmenovic, T.; Malic, T.; Vukasinovic-Vesic, M.; Andjelkovic, M.; Dikic, N. Overtraining as a risk factor for anterior cruciate ligament rupture in female basketball players. Br. J. Sports Med. 2017, 51, 392-393. [CrossRef]

6. Razak, A.H.; Zayegh, A.; Begg, R.K.; Wahab, Y. Foot Plantar Pressure Measurement System: A Review. Sensors 2012, 12, 9884-9912. [CrossRef]

7. Al-Angari, H.M.; Khandoker, A.H.; Lee, S.; Almahmeed, W.; Al Safar, H.S.; Jelinek, H.F.; Khalaf, K. Novel dynamic peak and distribution plantar pressure measures on diabetic patients during walking. Gait Posture 2017, 51, 261-267. [CrossRef]

8. Merriwether, E.N.; Sinacore, D. Impact of foot progression angle modification on plantar loading in individuals with diabetes mellitus and peripheral neuropathy. Edorium J. Disabil. Rehabil. 2016, 2, 15-23. [CrossRef]

9. Naemi, R.; Chatzistergos, P.; Suresh, S.; Sundar, L.; Chockalingam, N.; Ramachandran, A. Can plantar soft tissue mechanics enhance prognosis of diabetic foot ulcer? Diabetes Res. Clin. Pract. 2017, 126, 182-191. [CrossRef] 
10. Kong, P.W.; Lam, W.K.; Ng, W.X.; Aziz, L.; Leong, H.F. In-Shoe Plantar Pressure Profiles in Amateur Basketball Players Implications for Footwear Recommendations and Orthosis Use. J. Am. Podiatr. Med. Assoc. 2018, 108, 215-224. [CrossRef]

11. Serrano, C.; Sánchez-Sánchez, J.; López-Fernández, J.; Hernando, E.; Gallardo, L. Influence of the playing surface on changes of direction and plantar pressures during an agility test in youth futsal players. Eur. J. Sport Sci. 2020, 20, 906-914. [CrossRef] [PubMed]

12. Foss, K.D.B.; Myer, G.D.; Hewett, T.E. Epidemiology of Basketball, Soccer, and Volleyball Injuries in Middle-School Female Athletes. Physician Sportsmed. 2014, 42, 146-153. [CrossRef] [PubMed]

13. Krause, J.; Craig, N. Basketball Skills \& Drills; Human Kinetics: Champaign, IL, USA, 2019.

14. Buldt, A.K.; Allan, J.J.; Landorf, K.B.; Menz, H.B. The relationship between foot posture and plantar pressure during walking in adults: A systematic review. Gait Posture 2018, 62, 56-67. [CrossRef]

15. Lam, W.-K.; Ng, W.X.; Kong, P.W. Influence of shoe midsole hardness on plantar pressure distribution in four basketball-related movements. Res. Sports Med. 2017, 25, 37-47. [CrossRef] [PubMed]

16. Caselli, A.; Pham, H.; Giurini, J.M.; Armstrong, D.G.; Veves, A. The Forefoot-to-Rearfoot Plantar Pressure Ratio Is Increased in Severe Diabetic Neuropathy and Can Predict Foot Ulceration. Diabetes Care 2002, 25, 1066-1071. [CrossRef] [PubMed]

17. Hodge, M.C.; Bach, T.M.; Carter, G.M. Orthotic management of plantar pressure and pain in rheumatoid arthritis. Clin. Biomech. 1999, 14, 567-575. [CrossRef]

18. Kimmeskamp, S.; Hennig, E.M. Heel to toe motion characteristics in Parkinson patients during free walking. Clin. Biomech. 2001, 16, 806-812. [CrossRef]

19. Nieuwboer, A. Plantar force distribution in parkinsonian gait: A comparison between patients and age-matched control subjects. Scand. J. Rehabil. Med. 1999, 31, 185-192. [CrossRef]

20. Van Der Leeden, M.; Steultjens, M.; Dekker, J.H.M.; Prins, A.P.A. Forefoot joint damage, pain and disability in rheumatoid arthritis patients with foot complaints: The role of plantar pressure and gait characteristics. Rheumatology 2006, 45, 465-469. [CrossRef]

21. Wafai, L.; Zayegh, A.; Woulfe, J.; Aziz, S.M.; Begg, R.K. Identification of Foot Pathologies Based on Plantar Pressure Asymmetry. Sensors 2015, 15, 20392-20408. [CrossRef]

22. Claverie, L.; Ille, A.; Moretto, P. Discrete sensors distribution for accurate plantar pressure analyses. Med. Eng. Phys. 2016, 38, 1489-1494. [CrossRef] [PubMed]

23. Zulkifli, S.S.; Loh, W.P. A state-of-the-art review of foot pressure. Foot Ankle Surg. 2020, 26, 25-32. [CrossRef] [PubMed]

24. Feger, M.A.; Hertel, J. Surface electromyography and plantar pressure changes with novel gait training device in participants with chronic ankle instability. Clin. Biomech. 2016, 37, 117-124. [CrossRef] [PubMed]

25. Tang, U.H.; Zügner, R.; Lisovskaja, V.; Karlsson, J.; Hagberg, K.; Tranberg, R. Comparison of plantar pressure in three types of insole given to patients with diabetes at risk of developing foot ulcers-A two-year, randomized trial. J. Clin. Transl. Endocrinol. 2014, 1, 121-132. [CrossRef]

26. Moriguchi, M.; Maeshige, N.; Ueno, M.; Yoshikawa, Y.; Terashi, H.; Fujino, H. Modulation of plantar pressure and gastrocnemius activity during gait using electrical stimulation of the tibialis anterior in healthy adults. PLoS ONE 2018, 13, e0195309. [CrossRef] [PubMed]

27. Waaijman, R.; Bus, S.A. The interdependency of peak pressure and pressure-time integral in pressure studies on diabetic footwear: No need to report both parameters. Gait Posture 2012, 35, 1-5. [CrossRef]

28. Melai, T.; Ijzerman, T.H.; Schaper, N.C.; De Lange, T.L.; Willems, P.J.; Meijer, K.; Lieverse, A.G.; Savelberg, H.H. Calculation of plantar pressure time integral, an alternative approach. Gait Posture 2011, 34, 379-383. [CrossRef]

29. Ghasemi, A.; Zahediasl, S. Normality Tests for Statistical Analysis: A Guide for Non-Statisticians. Int. J. Endocrinol. Metab. 2012, 10, 486-489. [CrossRef]

30. Carpes, F.P.; Mota, C.B.; Faria, I.E. On the bilateral asymmetry during running and cycling-A review considering leg preference. Phys. Ther. Sport 2010, 11, 136-142. [CrossRef]

31. Viteckova, S.; Kutilek, P.; Svoboda, Z.; Krupicka, R.; Kauler, J.; Szabó, Z. Gait symmetry measures: A review of current and prospective methods. Biomed. Signal Process. Control 2018, 42, 89-100. [CrossRef]

32. Wu, C.L.; Hao, W.Y.; He, W.; Xiao, X.F.; Li, X.H.; Sun, W. Biomechanical and neuromuscular strategies on backward somersault landing in artistic gymnastics: A case study. Math. Biosci. Eng. 2019, 16, 5862-5876. [CrossRef] [PubMed] 
33. Zifchock, R.A.; Davis, I.; Higginson, J.; Royer, T. The symmetry angle: A novel, robust method of quantifying asymmetry. Gait Posture 2008, 27, 622-627. [CrossRef] [PubMed]

34. Ke, S.; Xie, H.; Sun, G.; Li, J. Study on Impact of Hardness of Sole on Force on Feet during Active Falling. In Proceedings of the 2018 International Conference on Sports, Arts, Education and Management Engineering (SAEME 2018), Taiyuan, China, 29-30 June 2018.

35. Teymouri, M.; Halabchi, F.; Mirshahi, M.; Mansournia, M.A.; Ahranjani, A.M.; Sadeghi, A. Comparison of plantar pressure distribution between three different shoes and three common movements in futsal. PLoS ONE 2017, 12, e0187359. [CrossRef] [PubMed]

36. Sterzing, T.; Frommhold, C.; Rosenbaum, D. In-shoe plantar pressure distribution and lower extremity muscle activity patterns of backward compared to forward running on a treadmill. Gait Posture 2016, 46, 135-141. [CrossRef]

37. Eils, E.; Streyl, M.; Linnenbecker, S.; Thorwesten, L.; Völker, K.; Rosenbaum, D. Characteristic Plantar Pressure Distribution Patterns during Soccer-Specific Movements. Am. J. Sports Med. 2004, 32, $140-145$. [CrossRef]

38. Wong, P.L.; Chamari, K.; Mao, D.W.; Wisløff, U.; Hong, Y. Higher plantar pressure on the medial side in four soccer-related movements. Br. J. Sports Med. 2007, 41, 93-100. [CrossRef]

39. Yu, B.; Preston, J.J.; Queen, R.M.; Byram, I.R.; Hardaker, W.M.; Gross, M.T.; Davis, J.M.; Taft, T.N.; Garrett, W.E. Effects of Wearing Foot Orthosis With Medial Arch Support on the Fifth Metatarsal Loading and Ankle Inversion Angle in Selected Basketball Tasks. J. Orthop. Sports Phys. Ther. 2007, 37, 186-191. [CrossRef]

Publisher's Note: MDPI stays neutral with regard to jurisdictional claims in published maps and institutional affiliations. 